\title{
OPINION AND EXPECTATION OF PHARMACISTS ON PROVIDING EXTEMPORANEOUS COMPOUNDING IN JOGJAKARTA AND CENTRAL JAVA PROVINCES, INDONESIA
}

\author{
CHAIRUN WIEDYANINGSIH ${ }^{*}$, SUSI ARI KRISTINA ${ }^{a}$, NIKEN NUR WIDYAKUSUMA ${ }^{a}$, HARDIKA ADITAMA ${ }^{a}$ \\ aManagement and Community Pharmacy Division, Department of Pharmaceutics, Faculty of Pharmacy, Universitas Gadjah Mada, \\ Yogyakarta, Indonesia \\ Email: chairun_wied@ugm.ac.id
}

Received: 08 Mar 2017 Revised and Accepted: 19 May 2017

\section{ABSTRACT}

Objective: This study was conducted to identify opinion and expectations of pharmacists on providing extemporaneous drug compounding to support pharmacy service.

Methods: The study was conducted in Indonesia. Twenty pharmacists, age 40 and above, working in Yogyakarta and Central Java provinces, participated in two focus group discussions (fgd) on extemporaneous drug compounding. Data was collected in June 2016. The data obtained from these groups was subjected to a qualitative analysis to identify recurrent themes pertaining to provision and regulation aspects of compounding.

Results: The findings indicated several characteristics of extemporaneous compounding opinion and expectation. These were broadly classified as 5 distinct themes. Evaluation of extemporaneous compounding products was the most prominent theme that was discussed in all of the focus groups. Other themes identified were the scope of compounding practice; materials, equipments and facilities; specialist compounding pharmacy; and prices. The results of this study may offer an excellent guided to designing effective interventions, which would provide regulatory recommendations for compounding pharmacy.

Conclusion: This study provided insight into the way that the pharmacists look at the extemporaneous compounding. It is recommended that the issues raised in this study be considered in future regulation of compounding pharmacy in Indonesia.

Keywords; Pharmacist, Expectation, Extemporaneous compounding, Service

(C) 2017 The Authors. Published by Innovare Academic Sciences Pvt Ltd. This is an open access article under the CC BY license (http://creativecommons.org/licenses/by/4.0/) DOI: http://dx.doi.org/10.22159/ijpps.2017v9i7.18358

\section{INTRODUCTION}

Among pharmacists, extemporaneous compounding is still debated. Extemporaneous compounding is needed since physicians sometimes change ingredient dose or combine ingredients to create a medication tailored to the needs of an individual patient. On the other hand, extemporaneous compounding medications is individualized and have not been well standardized $[1,2]$, which lead to poor quality products [1-3].

Frequent periodic prescription monitoring is an essential tool for better health care facilities [4]. Therefore, this study was conducted to identify opinion and expectations of pharmacists on providing extemporaneous drug compounding to support pharmacy service.

\section{MATERIALS AND METHODS}

This study was part of a Management and Community Pharmacy division Project funded by the faculty of Pharmacy Universitas Gadjah Mada to develop a model explaining the compounding pharmacy in Indonesia and recommendations for policy makers. A qualitative study was conducted to elicit pharmacists, opinions and expectation about compounding pharmacy. A total of two focus group discussion sessions were held in Yogyakarta.

\section{Recruitment of focus group participants}

Participants were pharmacists age $30 \mathrm{y}$ and above residing in Jogjakarta and Central Java. Participants were purposively selected in such a way as to ensure diversity of age, gender, professional experiences, clinical type and area to maximise the range of views expressed. Participants were recruited by Indonesia Pharmacists Association. Following completion of the discussions, participants received certificate and transport funding. All participants gave written informed consent prior to their participation

\section{Focus group topics}

The primary objective of this study was to elicit participant's opinion and expectations of extemporaneous drug compounding to support pharmacy service.

The following topics guided the focus group discussions.

Table 1: Topics guided the focus group discussions

Topics guided the focus group discussions
1. Focus areas in compounding pharmacy
2. Implementation and problems of compounding pharmacy
3. Standard of compounding pharmacy
4. How to get started in compounding pharmacy regulation.

\section{Data collection}

Following the approvals of local government, all participants were briefed about the study, given the opportunity to ask questions, and were asked for their written consent prior to the start of each session. Prior to data collection, a training session was held for the study facilitators. The fgd guideline was made available before the focus groups sessions. Two focus group sessions were held in Pharmacy faculty, Universitas Gadjah Mada, Yogyakarta, Indonesia. Data collection was done in July 2016. The focus group discussions activities were noted to ensure that no information was missed during the sessions. The study personnel present during the focus group sessions were the researchers, focus group facilitators, and the recorder. Using the guide topics listed on table 1and based on cues from each focus group session, the facilitator led the discussions while the study recorder transcribed the discussions. 


\section{Data analysis}

Detailed transcripts were reviewed by participants, then were analysed thematically. Descriptive categories were given either based on the words used by the participants, or from the researchers' theoretical knowledge. Each theme presented in the results was supported by quotations. The quotations cited here were translated from Indonesian into English. In translating the quotations from Indonesian to English, the effort was put into preserving the meaning of the quotation, rather than literally translating word for word. Parts of the quotations that were unnecessary or repetitious were excluded and indicated with an/./. Additions of words to facilitate the understanding of the quotation were put in square brackets.

\section{RESULTS}

Twenty participants participated. All participants were pharmacists, some of which were postgraduate. Besides practicing as private pharmacists, some participants worked in such teaching pharmacies. Characteristics of participants are given in table 2 .

Five categories were identified from the results of discussions regarding of compounding pharmacy, i.e., scope of compounding practice; materials, equipment and facilities; evaluation of extemporaneous compounding products; specialist compounding pharmacy; and prices

Table 2: Focus group participants' demographics

\begin{tabular}{ll}
\hline Demographics & N (20) \\
\hline Age & \\
$<30$ y & - \\
$30-40$ y & 12 \\
$40-50$ y & 6 \\
Sex & 2 \\
male & \\
female & 3 \\
Education & 17 \\
undergraduate & \\
postgraduate & 16 \\
Qualification profiles & 4 \\
teaching community pharmacy & \\
private community pharmacy & 6 \\
Practicing years & 14 \\
$<10$ yr & \\
10-20 yr & 4 \\
$20-30$ yr & 12 \\
$>30 y r$ & 2 \\
\hline
\end{tabular}

The results show that all participants provided and performed compounding pharmacy. It is also recognized by participants that compounding pharmacists were part of their competence

\section{Scope of compounding practice}

Pharmacies provided compounding generally based on orders from general practitioners and specialists. Children and the elderly were often the types of patients who benefit most from compounding. All participants extensively discussed the need for compounding pharmacies, since pharmacists have to be able to work with a variety of practice specialities, such as paediatrics, pain management, neurolog; cosmeceuticals, dentistry, and veterinary. Physicians may prescribed an individually compounded medication for a patient with an unusual health need. Some participants' statements on the issues are following,

“.. compounded medications usually ordered by pediatricians, neurolog, dermatologist."

“. compounded medications for adults [usually] for tb, asthma, epilepsy..."

Participants argued that compounding professionals can customize medications to fit each of individual treatment. Compounding provided physicians with expanded treatment options by providing dosage form and strength flexibility. Pharmacists may compound and supply extemporaneously prepared medicines in and from different types, involved solid, semi-solid and liquid types of compounding dosage form. The most common dosage form requested by physicians were 'puyer', which is powder, such solid dosage form for oral use in children. Examples of participants' statements are as follow,

". prescriptions. ask for compounded preparation in the form of puyer [powder, usually from crushed tablets and given in small sachets for oral use], ointment, lotion, capsules..."

"sometimes. . physicians ordered compounding for syrups...."

Participants argued that physicians prescribed compounded medicine because the formula in the form of the desired medicine was not available in commercial form. Example of participant statement is as follow,

“.... problems, such as-isoniazide and riphampicine, [the industrial did not produce anymore]. .therefore the medicine have to be compounded..".

\section{Materials, equipments and facilities}

Some issues were stated by some participants regarding to quality and safety of the products. Pharmacies that provided compounding services should pay attention about materials, equipments and facilities to produce a quality product. Compounding should be done in appropriate facilities, working environments, using quality materials and appropriate equipments. Further, guidance on the compounding was required to ensure the procedure and quality of product. Examples of the issues stated by participants are in the following statements

". . compounding drug preparation and equipments have to comply with requirements for human products. ."

". conventional tools are still used, so the result often vary from pharmacy to pharmacy."

". If the government wants to create a compounding regulation, the pharmaceutical industry should support the policy by providing the materials required in compounding"

“. . industry must know patients and pharmacies need...”

“. . problems related to raw materials. .."

Sanitation, cleanliness and hygiene became the interesting topic of discussions. Compounding technicians generally did not have an educational background in the field of health. Concern about hygiene was still lacking. Another interesting topic was the room for compounding. The compounding room generally was still distracted by other activities, since the room was not separated from one activity to another. Some suggestions for compounding has been expressed by the participants:

“.. compounding room is separated from activities. ."

"... hygiene is a concern..."

\section{Evaluation of extemporaneous compounding products}

Ensuring the quality and safety of compounding product was another concern generated during focus group discussions. Participants argued that the results of compounding will be qualified if comply to Standard Operating Procedure (SOP) for extemporaneous compounding. However, some pharmacies did not have the SOP. Another problem associated with compounding evaluation was documentation. The procedure and evaluation of each compounding formula has never been documented. Evaluation of products were generally done visually. Even, all of the fgd participants never evaluated their compounding products.

Some participants identified a lack of compounding product evaluation, such as follow:

“. . worry homogeneity and dosage [since did not evaluate results of the compounding]. ."

“. . determination of $\mathrm{pH}$, do not have a $\mathrm{pH}$ meter. ." 
“. . solubility problems [no references to overcome the problems]..."

“. . . hygroscopic [no references to overcome the problems]...."

“. . compounding results never been evaluated."

“. evaluation is still manual, visual. ."

". rifampisin is very hygroscopic, strongly attached to mortar [problems of procedure in compounding]."

\section{Specialist compounding pharmacy}

Pharmaceutical compounding is a branch of pharmacy that continues to play the crucial role of drug development. The role of pharmacy in compounding will grow in the next decade based on the assumption that new therapies will fail to meet the needs of all patients. Pharmacists must comply with all legislation relevant to the practice of extemporaneous compounding. However, all participants in fgd stated that they never heard about the laws, regulations and guidelines of compounding. It was necessary, therefore, to study and develop the extemporaneous compounding regulation. Some participants, even stated that pharmacists who are engaged in drug compounding shall be proficient in compounding and should continually expand their compounding knowledge by participating in seminars and/or studying appropriate literature. They should be knowledgeable about pharmaceutical compounding. Some statements and suggestions for compounding have been expressed by the participants as follow:

“. . .compounding is based solely on habits and experiences. .no specific guidelines [need expand their knowledge]. "

". standards for drug compounding has never existed. if there are guidelines for compounding. I strongly agree."

". . important for assessment pharmacy accreditation [regarding to improve services]."

". need experts in the field of compounding. so the results [compounding products] do not varies."

". . pharmacists and technicians should continually expand their compounding knowledge and skills."

“. pharmacists are protected. \{by law]."

". pharmacies provide compounding should have special permit [certificate of specialist compounding pharmacy]. Patients feel safe, protected from contamination and errors. "

\section{Prices}

Participants in fgd expressed deep concern over the consequences of compounding on prices. Participants suggested that the fee for the compounding listed on the sales receipt. The compounding fee should be paid based on the level of effort of the product compounded.

Some suggestions from the participants are as follow:

". fee for compounding should be considered."

". . fee of compounding should be printed on the receipt."

". . the price of compounding should be tailored to the level of effort."

\section{DISCUSSION}

In routine pharmacy practice, a small but significant proportion of medicines still needs to be prepared to meet the needs of individual patients. There was also evidence of a demand for a compounding service by physicians [1]. Extemporaneous compounding has been a core function for pharmacists. The symbol of the compounding role, the mortar and pestle, remains a widely recognised iconic image of pharmacy. Therefore, this study was conducted to identify opinion and expectations of the pharmacists on providing extemporaneous drug compounding to support pharmacy service. Five categories were identified from the results of discussions regarding of compounding pharmacy, i.e., the scope of compounding practice; materials, equipment and facilities; evaluation of extemporaneous compounding products; specialist compounding pharmacy; and prices.

When a drug is not available or is unavailable in a form suitable for a particular patient, compounding may provide a solution to the individual's needs. Extemporaneous compounding is 'the preparation and supply of a single unit of a product intended for immediate use by a specific consumer' [1-3]. The current study shows that in Indonesia, many pharmacies provided extemporaneous compounding. Mostly compounding involved modification of a manufactured product or the preparation of a compound from raw ingredients. In accordance with previous research $[1,3]$, the study also presents that most pharmacies performed basic compounding. Prescribers usually ordered nonsterile basic compounded preparation uses two or more medications combined into prescriptions. Similar with a previous study [1], the reasons of compounding usually involved pulveres form required but only tablets available, ointment required instead of cream; different dose or concentration required, discontinued unavailable medicine, compliance problems; or combining two ointments into one preparation. Therefore, compounding pharmacists have to work closely with the prescribing physician to ensure that patient goals were met. Since compounding was ordered by various physicians or specialities, therefore, the scopes of compounding practice should be divided based on the prescription complexity and the process that must be taken during compounding. The more complicated and time-consuming the procedure, the more likely it should be performed only in specialized pharmacies. Compounding has emerged as a specialized area of pharmacy practice [4]. As a speciality practice based on a patient-centered approach, compounding, was increasingly provided in Australia and the United States $[4,5]$. In the USA, approximately 3500 compounding pharmacies provided advanced compounding services that may include reformulation, alternative dosages and new packaging [6].

In developed countries, compounding pharmacies have access to sophisticated equipment, clean rooms; safety procedures; accredited training and education and testing labs for quality assurance. This situation was different with the existing compounding facilities in developing countries. As can be seen in the current study that conventional tools were still used for compounding the medicine, therefore the result often varied from pharmacy to pharmacy. Availability of raw materials were also such problems of compounding. Therefore, it was suggested that if the government wanted to create a compounding regulation, the pharmaceutical industry should also support the policy by providing the materials required in compounding. Hygiene was another problem encountered during fgd. Hygiene has to be considered during compounding preparations because it was still often ignored in compounding. Compounding drug preparation and equipment should have to comply with requirements for human products. The US Pharmacopea chapter 795 stated that compounding facilities should have an adequate space that was specifically designated for compounding of prescriptions. This space should provide for the orderly placement of equipment and materials to prevent mix-ups among ingredients, containers, labels, in-process materials, and finished preparations and was designed, arranged, and used to prevent adventitious cross-contamination. Some complex compounding prescriptions were more difficult to compound and required special handling during the compounding process. Thus, special care and equipments were required.

In Indonesia, most compounding was ordered for oral and topical medications. Pharmacists should responsible for ensuring that extemporaneous preparations were compounded according to compounding guidelines and standards. All compounding products should be free of contamination. However, most pharmacies did not have specific compounding guideline and standard. Pharmacists generally did not evaluate their compounding products. Common problems pharmacists encountered in evaluation of compounding products were stability, solubility and homogeneity. Pharmacists usually evaluated their compounding simply, even conventionally.

The responsibility to compound safe was fundamental to the pharmacy profession [7]. Pharmacists are expected to be experts 
about medicines [8]. The current study shows that pharmacists usually prepared compounding based solely on habits and experiences. This was because pharmacies did not have specific standard or guideline of compounding. Compounding pharmacists, therefore, have to be properly trained to specialize in this aspect of pharmacy practice and must have the appropriate resources and references to compound quality medications. The results of the study shows that continuing education program for pharmacists and technicians to specialize aspect of compounding was expected. Educational institutions were expected to keep providing such training programs to improve knowledge and skills of compounding. In developed country, such the US, some pharmacists have elected to focus their practice in compounding area and have additional experience, education, and training [9]. In 2004, the Pharmacy Compounding Accreditation Board (PCAB) was established and was an important development impacting the practice of pharmacy compounding [9]. PCAB accreditation has been recognized by the American Medical Association and the American Pharmacists Association as a way to identify compounding pharmacies that meet high-quality standards. In Yogyakarta city, Indonesia, the number of pharmacies is quite a lot which is more than 100 pharmacies. Assessment of the quality of pharmaceutical services in community pharmacies has been implemented in Yogyakarta. However, the accreditation for pharmaceutical services did not include the specialist of compounding. The current study presents the importance of assessing the sustainability of pharmaceutical services in community pharmacies. Improvement the assessment criteria, such as pharmaceutical compounding specialist will certainly be very beneficial for patients and pharmacists. The current study also shows suggestion that pharmacies provided compounding should have a special permit, such certificate of specialist compounding pharmacy. The certificate is very important for the pharmacy to improve the level of accreditation and becoming important with regard to legal protection. Therefore, community pharmacies provided specialist compounding, pharmacists and staff were more likely to have undertaken further training in compounding. A greater professional service orientation was apparent in specialized compounding pharmacies [10]. The specialized compounding pharmacies were more likely to interact with a greater variety of prescribers of compounds. Although pharmacies could provide compounding, there should be accreditation of specialized practices [11].

For some time now, pharmacists across Yogyakarta have been providing many valuable services without receiving compensation. The current study presents the need to determine the cost of compounding. Compounding may or may not cost more than conventional medication. Its cost depends on factors such as the type of ingredients and equipment required, as well as the time of the pharmacist spends researching and preparing the medication. The more complex a medication is to make, the more compounding cost should be associated with the final price of the product. Establishing a minimum compounding fee and professional fee can prevent pharmacists from being underpaid. Therefore, the pharmacist should ensure that the fee was reasonable.

\section{Limitations and future research}

The study looked at the pharmacists' opinion and expectation about compounding pharmacy in community pharmacies. The results were very positive; however, as the study only looked at Jogjakarta and Central Java provinces, these findings may not be translated to pharmacists of other provinces in Indonesia. Other limitations in this study were the lack of adequate information given by participants due to a limited number of groups in fgd and tendency of certain types of the participant to dominate the discussion process. There was also a room for improvement, especially in finding participants' opinion more deeply. Therefore, more number of groups of discussion and more specific questions are needed for a complete research in the future.

\section{CONCLUSION}

Pharmaceutical compounding was the root of the pharmacy profession. This study shows that pharmacists need clear guidelines for assurances of product safety. Materials, equipment and facilities, as well as product prices, should also be considered when providing extemporaneous drug compounding. Therefore, excellent guided to design uniform standard and regulation of compounding was required for appropriate practice and pharmacists law protection.

\section{AUTHORS' CONTRIBUTION}

CW developed the concept; designed the study and wrote the manuscript. CW and SAK developed the methodology. CW; SAK; NNW; and HA collected the data. CW and NNW performed the analysis. All authors discussed the results and commented on the manuscript at all stages.

\section{CONFLICT OF INTERESTS}

Declared none

\section{REFERENCES}

1. Wiedyaningsih C, Suryawati S, Soenarto Y, Hakimi M. Beliefs about the use of extemporaneous compounding for paediatric outpatients among physicians in Yogyakarta, Indonesia. Int J Pharm Sci Rev Res 2016;41:22-6.

2. Kristina SA, Wiedyaningsih C, Widyakusuma NN, Aditama H. Extemporaneous compounding practice by pharmacists: a systematic review. Int J Pharm Pharm Sci 2017; 9:42-6.

3. Wiedyaningsih C, Suryawati S, Soenarto Y, Hakimi M. The use of the theory of planned behavior to predict factors influencing physicians' decision to prescribe extemporaneous compounding dosage form for pediatric outpatients. Asian J Pharm Clin Res 2016;9:288-91.

4. Madarkar M, Kambil SM, Bath RM, Sukumar D. Pattern of prescribing practices of topical corticosteroids in the outpatient dermatology department of tertiary care hospital. Asian J Pharm Clin Res 2015;8:149-51.

5. Giam JA, McLachlan AJ, Krass I. Community pharmacy compounding-impact on professional status. Int J Clin Pharm 2011;33:177-82.

6. Lau ETL, Jones AL, Kairuz T, Nissen LM, Steadman KJ. Compounding practices in queensland: experiences and perceptions of pharmacists and pharmacy students. J Pharm Pract Res 2013;43:19-24.

7. Foehr ED. Compounding pharmacies: how to navigate the new regulatory and business environment and ensure high quality, safe products, which are cost effective. Pharm Pharmacol Int J 2014;1:00005.

8. Prioste T, Magon TS, Fagundes V, Montanha MC, Moriwaki C, Kimura E. Recovery of drug residues in equipment and utensils used by compounding pharmacies after standard cleaning procedure. Braz J Pharm Sci 2015;51:317-22.

9. Dawodu P, Rutter P. How do pharmacists construct, facilitate and consolidate their professional identity? Pharm MDPI 2016;4:1-6

10. A Resource Paper of the Council on Credentialing in Pharmacy, Scope of Contemporary Pharmacy Practice: Roles, Responsibilities, and Functions of Pharmacists and Pharmacy Technicians; 2009. Available from: http://www. pharmacycredentialing.org/Contemporary_Pharmacy_Practice. pdf. [Last accessed on 08 Mar 2017]

11. Giam JA, McLachlan AJ, Krass I. Specialized compounding in community pharmacies: an organizational perspective. J Am Pharm Assoc 2010;50:354-61.

12. Giam JA, McLachlan AJ, Krass I. Specialised compounding practices and opinions of Australian community pharmacists. J Pharm Pract Res 2007;37:260-4.

\section{How to cite this article}

- Chairun Wiedyaningsih, Susi Ari Kristina, Niken Nur Widyakusuma, Hardika Aditama. Opinion and expectation of pharmacists on providing extemporaneous compounding in jogjakarta and central java provinces, Indonesia. Int J Pharm Pharm Sci 2017;9(7):79-82. 